\title{
Mental Toughness in Competitive Tennis: Relationships with Resilience and Stress
}

\author{
Richard G. Cowden ${ }^{1,2 *}$, Anna Meyer-Weitz ${ }^{2}$ and Kwaku Oppong Asante ${ }^{2}$ \\ ${ }^{1}$ Institute of Psychology and Wellbeing, North-West University, Potchefstroom, South Africa, ${ }^{2}$ Discipline of Psychology, \\ University of KwaZulu-Natal, Durban, South Africa
}

The present study investigated the relationships between mental toughness (MT), resilience, and stress among competitive South African tennis players. A total of 351 tennis players participating at various competitive standards completed the Sports Mental Toughness Questionnaire, the Resilience Scale for Adults, and a modified version of the Recovery-Stress Questionnaire for Athletes. The results indicated that total MT was positively associated with total resilience $(r=0.59)$, but negatively associated with total stress $(r=-0.44)$. The resilience subscales of perception of self, perception of future, social competence, and social resources, but not family cohesion, significantly predicted total MT $\left(R^{2}=0.35\right)$. Both total resilience and total MT significantly predicted total stress $\left(R^{2}=0.21\right)$. Based on the findings, interrelations between MT and resilience

OPEN ACCESS

Edited by:

Guy Cheron,

Université Libre de Bruxelles, Belgium

Reviewed by:

Leapetswe Malete,

University of Botswana, Botswana Jamie Alan Taylor,

University of Central Lancashire, UK

${ }^{*}$ Correspondence:

Richard G. Cowden

richardgregorycowden@gmail.com

Specialty section:

This article was submitted to Movement Science and Sport

Psychology,

a section of the journal

Frontiers in Psychology

Received: 25 August 2015

Accepted: 21 February 2016

Published: 15 March 2016

Citation:

Cowden RG, Meyer-Weitz A and Oppong Asante K (2016) Mental Toughness in Competitive Tennis:

Relationships with Resilience and Stress. Front. Psychol. 7:320. doi: 10.3389/fpsyg.2016.00320 are explored, implications outlined, and additional research is suggested to ascertain the contextual relevance and outcomes associated with each construct in sport.

Keywords: mental toughness, resilience, stress, sport, competitive tennis

\section{INTRODUCTION}

Highly competitive sporting contexts emphasize the necessity to emerge as victor and accentuate the winning is considered the only option mentality. With success often bestowed solely upon winners or champions, the pursuit of sporting achievement has generated interest in determining the underlying characteristics of successful athletes (Hardy et al., 2014). Recent research attention has been directed toward mental toughness (MT), which has developed considerably from a historically heuristic basis (e.g., Loehr, 1986) and a time in which "virtually any desirable positive psychological characteristic associated with sporting success (had) been labeled as MT" (Jones et al., 2002, p. 206).

There is growing consensus about the central components of MT (Crust, 2008; Gucciardi et al., 2011) and research has contributed to refining the conceptualization, operationalization, and measurement of the construct. However, despite the advancement in understanding MT, a single, homogenous, and collectively agreed upon definition of MT remains absent (Tibbert et al., 2015). For instance, Clough et al. (2002) provide a dispositional or trait-like definition of MT, Jones et al. (2002) define the construct in terms of what MT enables athletes to achieve, and Coulter et al. (2010) assert MT as a process involving the interaction between a selection of psychobehavioral characteristics, the environment, and outcomes.

The definitional discrepancies expound the conceptual ambiguity surrounding MT, including whether it is a personality disposition (Horsburgh et al., 2009) or is amenable to interventions and developmental experiences (Parkes and Mallett, 2011; Mahoney et al., 2014). In addition, prior research has evidenced sport-specific differences in the type (Gucciardi et al., 2008) and degree 
(Gucciardi, 2009) of MT, culminating in the development of sport-specific MT inventories [e.g., Cricket Mental Toughness Inventory (CMTI); Gucciardi and Gordon, 2009]. Though extensive research involving single sports has been conducted (e.g., rugby, soccer, Australian Rules football, and cricket), competitive tennis has received comparably less MT research attention (Cowden et al., 2014).

The uniqueness of competitive tennis participation suggests MT in tennis may differ from other sports. Specifically, tennis requires athletes to frequently adapt to a variety of environmental conditions (e.g., weather) as well as playing surfaces (e.g., indoor hard court, clay). Contrasting other sports (e.g., soccer), tennis players are restricted from communicating, interacting, or seeking guidance from their coaching or support personnel during competition (Cowden et al., 2014). Also, the year-round competitive tennis season requires athletes to sustain physical and mental performance levels for protracted periods of time. Therefore, investigating MT in tennis (and other sport codes) may provide further indications of sport-specific types and manifestations of MT.

Collectively, the aforementioned issues have contributed to critical debates on the conceptual make-up and measurement of MT (e.g., Clough et al., 2012; Gucciardi et al., 2012; Perry et al., 2013). Notwithstanding the continued deliberations on the concept and definition of MT, for the purpose of this study, MT is defined as a collection of reasonably stable, advantageous characteristics that facilitate positive responses to the demands and pressures of sport participation (Sheard et al., 2009).

\section{Related Constructs: The Exemplar of Resilience}

Conceptual disparities also appear to relate to the similarities between MT and other related constructs that may have been appropriated into the underpinning of MT. For instance, Clough et al. (2002) used hardiness (i.e., having a personal sense of control, resolute commitment, and perceiving challenges as opportunities; Kobasa et al., 1982) as a framework for conceptualizing MT. Clough et al. (2002) suggest that, although the constructs are both distinct and related, confidence (as a component of MT) is the distinguishing attribute between the two. Along similar lines, Cowden et al. (2014) found a positive association between MT and learned resourcefulness (i.e., a collection of learned abilities that regulate potentially detrimental cognitive-affective experiences to sustain or maintain functioning; Rosenbaum, 1990). The finding was attributed to the plausible convergence or similarities between the constructs (i.e., comprised of several constituents, superior control), but the authors noted the unexplained variance of MT (38\%) may signify divergence between the constructs (i.e., commitment, achievement motivation).

Resilience is another construct that is noticeably similar to MT. Like MT, the definition of resilience remains a contentious area (Herrman et al., 2011). Conceptual differences also exist, such as whether resilience is an outcome (Mancini and Bonanno, 2009) or a process (Luthar and Cicchetti, 2000). However, Windle (2011, P. 163) proffers a recent definition of resilience as "the process of effectively negotiating, adapting to, or managing significant sources of stress or trauma. Assets and resources within the individual, their life and environment facilitate this capacity for adaptation and 'bouncing back' in the face of adversity".

The notion of effectively overcoming and dealing with pressure, challenges, and stressors has been explicated in several descriptions of MT (e.g., Clough et al., 2002; Jones et al., 2002; Bull et al., 2005), which is arguably the strongest link between the two constructs. Galli and Vealey (2008) found that athletes make use of personal, social, and cultural factors to overcome various adversities in sport (e.g., periods of performance slumps). Fletcher and Sarkar (2012) identified several types of stressors that Olympic athletes successfully overcame through the use of psychological factors (e.g., positive personality, motivation, confidence, focus) that promote facilitative responses and positive sport performance outcomes. These factors resemble a number of characteristics associated with MT, including optimism (Nicholls et al., 2008), confidence or self-belief (Clough et al., 2002; Gucciardi and Gordon, 2009), concentration (Jones et al., 2007), and achievement motivation (Connaughton and Hanton, 2009).

Due, in part, to the apparent overlap between MT and resilience, there have been suggestions of the interrelatedness between the constructs. Loehr (1995) was among the first to posit emotional resilience as an aspect of MT and recent qualitative investigations have asserted resilience as a subcomponent of MT in sport (Gucciardi et al., 2008; Coulter et al., 2010), which have culminated in selected MT instruments specifying resilience as a subscale (e.g., CMTI; Gucciardi and Gordon, 2009).

Mental toughness and resilience, however, are dissimilar in several ways. There are assertions that resilience applies primarily to negative contexts, whereas MT also applies to positive circumstances (Gucciardi et al., 2008; Sheard, 2013). MT represents a set of personal attributes that influence the manner in which adversity, challenges, and goals are appraised and approached (Gucciardi et al., 2009b). Resilience, on the other hand, is associated with the possession of and/or the presence of protective (e.g., personal, familial, community; Kumpfer, 1999) and vulnerability factors that influence the risk-positive adaptation relationship (Punamaki et al., 2006). Thus, unlike MT, resilience seems to include a range of influential qualities outside of the self (e.g., perceived social support; Fletcher and Sarkar, 2012).

Perhaps for this reason, Gerber et al. (2013a) examined and supported the protective resource quality of MT among adolescents that were clustered according to resilient outcome categories (i.e., well-adjusted, maladjusted, deteriorated, and resilient groups). The students clustered into resilient and deteriorated groups did not differ on baseline levels of MT, but the resilient cluster displayed greater MT at the 10-month follow-up. In another study, Gerber et al. (2013b) found that MT moderated the stress-depressive symptom relationship, with lower levels of depression among adolescents high in MT, regardless of stress levels. However, neither study directly measured resilience using a validated instrument, which precludes a clear determination of the relationship between MT and resilience. 
Nonetheless, the findings emphasize MT as a resilience resource or protective factor that moderates the association between risk and adaption levels to facilitate positive outcomes (Gerber et al., 2013a,b).

With the obscurity that exists about the manner in which MT and resilience are related, quantitative MT-resilience investigations may contribute to delineating the similarities and differences between the two constructs. This includes whether resilience is a component of MT, whether MT is a protective factor in the resilience process, or whether the relevance of one construct to the other is dependent on particular situations or contexts. For instance, MT may contribute to resilient outcomes as a personal protective factor or resource. Selected types of resilience, on the other hand, may apply to MT based on a specific type of situation, such as personal resources applying primarily during competitive situational adversity (e.g., when behind in a match) and social resources required following a disappointing loss in order to rebound quickly.

\section{Mental Toughness and Resilience: Positive Adaptation to Stress Commonality}

During exposure to internal and external demands to which consequences are ascribed, the concept of stress refers to disequilibrium between such demands (i.e., stressors) and the ability to successfully meet them (McGrath, 1970; Fletcher et al., 2006). Acknowledging the potentially deleterious effects of stress on an athlete's mental and physical wellbeing (Crocker et al., 2015), MT and resilience are both comparably important for successfully dealing with stressors or avoiding the effect of stress as athletes pursue performance excellence (Gucciardi et al., 2008; Fletcher and Sarkar, 2012).

Although few quantitative studies involving resilience and stress in sport have been conducted, MT has received some attention in relation to stress. Mentally tougher individuals tend to report stressors as being less intense, perceive greater control over the stressors they are confronted with (Kaiseler et al., 2009), and report lower levels of depression despite perceptions of stress (Gerber et al., 2013b). Due to the conceptual overlap in the ability to bounce back from or overcome adversity and stress between MT and resilience, determining whether resilience and MT are, conjunctively, associated with lower levels of stress may provide additional insight into the similarities and distinctions between the constructs.

The purpose of the present study, therefore, was to explore the relationships between MT and resilience, MT and stress, and the role of resilience and MT in relation to stress. In particular, the following hypotheses were tested: (a) MT would be positively related to resilience, (b) MT would be predicted by the resilience resource domains (i.e., subscales), (c) MT would be negatively related to stress, and (d) MT and resilience would both be predictors of stress.

\section{MATERIALS AND METHODS}

\section{Participants}

The sample included 185 male and 166 female competitive South African tennis players ranging from 18 to 84 years of age $(M$ age $=28.91$ years, $S D=13.87)$. The participants had played tennis for a minimum of 5 years $(M$ age $=16.87$ years, $S D=12.17)$ and had competed in a competitive tennis event within the last 2 weeks prior to participation in the study. The participants were purposively recruited through local and national South African tennis organizations, universities, and tournaments. The participants competed at international $(N=33)$, national $(N=78)$, university team/league $(N=156)$, local county $(N=23)$, and county club $(N=61)$ tournament levels.

\section{Materials}

\section{Mental Toughness}

The Sports Mental Toughness Questionnaire (SMTQ; Sheard et al., 2009) was used to assess MT. The SMTQ is a 14item Likert-type instrument and a multidimensional measure of MT along three subscales: confidence (e.g., "I have qualities that set me apart from other competitors"), constancy (e.g., "I get distracted easily and lose my concentration"), and control (e.g., "I worry about performing poorly"). CFA evidenced strong support for the hierarchical three-factor model, with a goodness-of-fit index (GFI) of 0.95 denoting good model fit (Sheard et al., 2009). The coefficients between the higherorder factor of total MT and second-order factors of confidence $(r=0.72)$, constancy $(r=0.71)$, and control $(r=0.66)$ were considered acceptable. Correlations between confidence and control, confidence and constancy, and constancy and control were $0.28,0.31$, and 0.31 , respectively (Sheard et al., 2009). The authors also reported acceptable internal consistency estimates for global MT and each of the subscales $(\alpha=0.72-0.81$; Sheard et al., 2009).

Providing evidence for the divergent validity of the measure, correlations between the SMTQ and the subscales on the Life Orientation Test, Personal View Survey III-R, and the Positive and Negative Affect Schedule were moderate and ranged from 0.23 to $0.38,0.14$ to 0.33 , and 0.12 to 0.49 , respectively (Sheard et al., 2009). The discriminative power of the SMTQ has also been demonstrated based on statistically meaningful differences between athletes of dissimilar competitive levels, ages, and gender, with higher scores for more advanced competitive levels, for older athletes, and males (Sheard et al., 2009).

In the present study, Cronbach's alpha was 0.74 for total MT, 0.64 for confidence, 0.52 for constancy, and 0.67 for control. Although confidence and control evidenced questionable internal consistency (George and Mallery, 2003), alpha is susceptible to underestimating internal consistency on scales with low item numbers (Briggs and Cheek, 1986). As a result, the subscales of confidence and control were retained for statistical computations. The poor internal consistency for constancy, however, resulted in the exclusion of the scale from subscale analyses. 


\section{Resilience}

The Resilience Scale for Adults (RSA; Friborg et al., 2005) was used to measure resilience. The RSA has been validated on several occasions (e.g., Hjemdal et al., 2011; Capanna et al., 2015) and is a comprehensive measure of resilience protective factors. The 33-item inventory is rated on a 5-point semantic differential scale with opposing attributes at each end of scale for each item. The questionnaire encompasses six domains of resilience: social competence (e.g., "When I am with others: I easily laugh - I seldom laugh"), social resources (e.g., "I get support from: Friends/family members - No one"), family cohesion (e.g., "In difficult periods my family: Keeps a positive outlook on the future - Views the future as gloomy"), structured style (e.g., "I am good at: Organizing my time Wasting my time"), personal strength/perception of self (e.g., "My abilities: I strongly believe in - I am uncertain about"), and personal strength/perception of future (e.g., "My future goals: I know how to accomplish - I am unsure how to accomplish").

Friborg et al. (2005) reported the internal consistency values for each subscale as ranging from 0.66 to 78 . Research has supported the convergent, criterion, and discriminant validity (Friborg et al., 2003; Friborg et al., 2005; Hjemdal et al., 2011; Capanna et al., 2015) of the measure. In this study, Cronbach's alpha for total resilience (0.89), perception of self (0.70), social competence (0.77), family cohesion (0.81), and social resources ( 0.81 ) were acceptable to strong (Nunnally and Bernstein, 1994). Despite the internal consistency for perception of future (0.67) and structured style (0.48) being questionable and poor, respectively (George and Mallery, 2003), alpha may be underestimated on scales with low item numbers (Briggs and Cheek, 1986). As a result, perception of future was retained in subsequent subscale analyses, though the structured style subscale was not.

\section{Stress}

A modified version of the Recovery-Stress Questionnaire for Athletes (RESTQ; Kellmann and Kallus, 2001) was used to examine stress. Specifically, only the stress-related items were administered to the participants. Therefore, 40 of the original 76 items were retained for use in the current study. The items are rated on a 7-point Likert-type scale anchored at 0 (never) and 6 (always) and address the degree to which the participants experienced the item in the past 3 days/nights. The items comprise 10 dimensions of stress (four items for each factor), which permits the assessment of the stress experienced by athletes in a broad range of aspects inside and outside of sport.

Seven of the scales measure a general stress domain, comprising the subscales of general stress (e.g., "I was fed up with everything"), emotional stress (e.g., "I felt anxious or inhibited"), social stress (e.g., "I was annoyed by others"), conflicts/pressure (e.g., "I couldn't switch my mind off"), fatigue (e.g., "I did not get enough sleep"), lack of energy (e.g., "I was unable to concentrate well"), and somatic complaints (e.g., "I felt physically bad"). Three subscales measure sport stress, which are labeled disturbed breaks (e.g., "I could not get rest during the breaks"), burnout/exhaustion (e.g., "I felt burned out by my sport"), and fitness/injury (e.g., "I felt vulnerable to injuries").

The inventory has been validated using PCA (Kellmann and Kallus, 2001), a finding that has been cross-culturally verified (e.g., Gonzalez-Boto et al., 2008; Nederhof et al., 2008). Similar internal consistency estimates have been reported across studies (Kellmann and Kallus, 2001; Gonzalez-Boto et al., 2008; Nederhof et al., 2008). Kellmann and Kallus (2001) also found appropriate test-retest reliability estimates and support for the construct validity of each subscale. In this study, the relevant subscales were summated to obtain general and sport domains of stress as well as total stress. The internal consistency estimates were strong for total $(\alpha=0.96)$, general $(\alpha=0.93)$, and sport $(\alpha=0.86)$ stress.

\section{Procedure}

Following the attainment of relevant gatekeeper permission and Ethical Clearance from the University of KwaZulu-Natal's Human and Social Sciences Research Ethics Committee, various tournament, university, and tennis organization directors were approached to obtain permission to access the participants. Based on athletes' availability, the self-completed questionnaires were administered in groups of 5-10 players. The purpose of the study was explained to the participants, informed consent was outlined, and each participant completed an informed consent document prior to his or her participation. For each instrument, the athletes were prompted to consider and respond to the items according to the extent to which each item applied to them in relation to their involvement in competitive tennis. The inventories required approximately $20 \mathrm{~min}$ to complete.

\section{Data Analyses}

The Statistical Package for Social Sciences (SPSS 23) was used to conduct all statistical tests. Prior to proceeding with statistical analyses, the hypothesis testing assumptions, including normality and homoscedasticity, were performed. The descriptive statistics and Pearson correlations (one-tailed) that were used to examine the relationships between the MT, resilience, and stress scales are reported in Table 1. Multiple linear regression analyses, using the stepwise forward selection method (alpha to enter $=0.05$, alpha to exit $=0.10$ ), are presented in Table 2 . An alpha level of 0.05 was used for all statistical tests. For each variable, greater scores are associated with higher levels of the characteristic.

\section{RESULTS}

\section{Relationships Among All Variables}

Total MT was positively correlated with total resilience $(r=0.59)$ and the subscales of resilience $(r=0.35-0.53)$, which, according to Cohen's (1992) effect size standards, were medium to large in effect size. Total MT correlated negatively with total stress $(r=-0.44)$, general stress $(r=-0.46)$, and sport stress $(r=-0.32)$, which were medium and medium-to-large in effect size (Cohen, 1992). 
TABLE 1 | Pearson correlations among all scales and subscales.

\begin{tabular}{|c|c|c|c|c|c|c|c|c|c|c|c|c|}
\hline Variable & (1) & (2) & (3) & (4) & (5) & (6) & (7) & (8) & (9) & (10) & (11) & (12) \\
\hline (1) Total mental toughness & - & $0.77^{* *}$ & $0.74^{* *}$ & $0.59 * *$ & $0.53^{* *}$ & $0.41^{* *}$ & $0.35^{* *}$ & $0.42^{* *}$ & $0.43^{* *}$ & $-0.44^{* *}$ & $-0.46^{* *}$ & $-0.32^{* *}$ \\
\hline (2) Confidence & - & - & $0.27^{* *}$ & $0.48^{* *}$ & $0.47^{* *}$ & $0.31^{* *}$ & $0.32^{* *}$ & $0.29 * *$ & $0.33^{* *}$ & $-0.24^{* *}$ & $-0.27^{* *}$ & $-0.12^{*}$ \\
\hline (3) Control & - & - & - & $0.33^{* *}$ & $0.30^{* *}$ & $0.24^{* *}$ & $0.20 * *$ & $0.26^{* *}$ & $0.22 * *$ & $-0.45^{* *}$ & $-0.46^{* *}$ & $-0.35^{* *}$ \\
\hline (4) Total resilience & - & - & - & - & $0.72^{* *}$ & $0.65^{* *}$ & $0.67^{* *}$ & $0.81^{* *}$ & $0.80^{* *}$ & $-0.36^{* *}$ & $-0.36^{* *}$ & $-0.26^{* *}$ \\
\hline (5) Perception of self & - & - & - & - & - & $0.47^{* *}$ & $0.38^{* *}$ & $0.45^{* *}$ & $0.46^{* *}$ & $-0.32^{* *}$ & $-0.34^{* *}$ & $-0.20^{* *}$ \\
\hline (6) Perception of future & - & - & - & - & - & - & $0.25^{* *}$ & $0.42^{* *}$ & $0.36^{* *}$ & $-0.23^{* *}$ & $-0.22^{* *}$ & $-0.20^{* *}$ \\
\hline (7) Social competence & - & - & - & - & - & - & - & $0.39 * *$ & $0.46^{* *}$ & $-0.23^{* *}$ & $-0.26^{* *}$ & $-0.12^{*}$ \\
\hline (8) Family cohesion & - & - & - & - & - & - & - & - & $0.69 * *$ & $-0.27^{* *}$ & $-0.28^{* *}$ & $-0.21^{* *}$ \\
\hline (9) Social resources & - & - & - & - & - & - & - & - & - & $-0.26^{* *}$ & $-0.26^{* *}$ & $-0.21^{* *}$ \\
\hline (10) Total stress & - & - & - & - & - & - & - & - & - & - & $0.97^{* *}$ & $0.85^{* *}$ \\
\hline (11) General stress & - & - & - & - & - & - & - & - & - & - & - & $0.71^{* *}$ \\
\hline (12) Sport stress & - & - & - & - & - & - & - & - & - & - & - & - \\
\hline M & 41.35 & 18.15 & 10.37 & 133.72 & 24.29 & 16.42 & 23.02 & 24.40 & 30.31 & 93.27 & 65.71 & 27.56 \\
\hline$S D$ & 4.85 & 2.36 & 2.34 & 15.79 & 3.45 & 2.83 & 4.45 & 4.37 & 4.23 & 29.76 & 21.99 & 9.83 \\
\hline
\end{tabular}

${ }^{*} p<0.05$ (one-tailed), ${ }^{* *} p<0.001$ (one-tailed).

TABLE 2 | Multiple linear regression analyses (stepwise forward selection) predicting mental toughness and stress.

\begin{tabular}{|c|c|c|c|c|c|c|c|}
\hline \multirow[t]{2}{*}{ Model } & \multirow[b]{2}{*}{ Predictor } & \multicolumn{3}{|c|}{ DV $=$ Total mental toughness } & \multicolumn{3}{|c|}{ DV = Total stress } \\
\hline & & $B$ & $\beta$ & $95 \% \mathrm{Cl}$ for $\mathrm{B}$ & $B$ & $\beta$ & $95 \% \mathrm{Cl}$ for $\mathrm{B}$ \\
\hline \multirow[t]{8}{*}{ Model 1} & (Constant) & 17.03 & & {$[13.45,20.61]$} & & & \\
\hline & Perception of self & $0.46^{* *}$ & 0.33 & {$[0.32,0.61]$} & & & \\
\hline & Social resources & $0.20 * *$ & 0.18 & {$[0.08,0.32]$} & & & \\
\hline & Perception of future & $0.26^{* *}$ & 0.15 & {$[0.09,0.43]$} & & & \\
\hline & Social competence & $0.12^{*}$ & 0.11 & {$[0.01,0.23]$} & & & \\
\hline & Family cohesion & - & - & - & & & \\
\hline & $R^{2}$ & 0.35 & & & & & \\
\hline & $F$ & $45.59^{* *}$ & & & & & \\
\hline \multirow[t]{5}{*}{ Model 2} & (Constant) & & & & 220.23 & & {$[193.51,246.95]$} \\
\hline & Total mental toughness & & & & $-2.20^{* *}$ & -0.36 & {$[-2.91,-1.49]$} \\
\hline & Total resilience & & & & $-0.27^{*}$ & -0.14 & {$[-0.49,-0.05]$} \\
\hline & $R^{2}$ & & & & 0.21 & & \\
\hline & $F$ & & & & $46.13^{* *}$ & & \\
\hline
\end{tabular}

$\mathrm{Cl}=$ confidence interval. ${ }^{*} p<0.05,{ }^{*} p<0.001$.

\section{Predicting Mental Toughness: Resilience}

Multiple linear regression was used to determine the extent to which the five subcomponents of resilience (the structured style subscale was excluded) predicted total MT. Perception of self $(\beta=0.33, p<0.001)$, social resources $(\beta=0.17, p=0.001)$, perception of future $(\beta=0.15, p=0.003)$, and social competence ( $\beta=0.11, p=0.028)$ were statistically significant predictors of MT ( $F=46.07, R^{2}=0.35,95 \%$ CI for $R^{2}[0.27-0.43], p<0.001$; see Table 2). The family cohesion $(p=0.218)$ subscale was not a statistically significant predictor of total MT.

\section{Predicting Stress: Mental Toughness and Resilience}

Multiple linear regression was computed with total stress as the dependent variable and total MT and total resilience as the predictors. The results indicated that total MT $(\beta=-0.36$, $p<0.001)$ and total resilience $(\beta=-0.14, p=0.016)$ were both significant predictors of total stress $\left(F=46.13, R^{2}=0.21,95 \% \mathrm{CI}\right.$ for $R^{2}$ [0.13-0.29], $p<0.001$; see Table 2).

\section{DISCUSSION}

The purpose of the present study was to explore the relationships between MT, resilience, and stress among competitive tennis players. Based on the results, the hypotheses that (a) MT and resilience would be positively related, (c) MT would be negatively associated with stress, and (d) both MT and resilience would significantly predict stress were all supported. The hypothesis that (b) MT would be significantly predicted by each of the resilience subdomains was partially supported, with one subscale (family cohesion) not found to be a significant predictor of MT. 


\section{Mental Toughness and Resilience}

The strong positive association between MT and resilience may demonstrate the conceptual parallels between the two constructs. That is, both resilience and MT are associated with effective adaptation, coping, maintaining functioning or performance, and achieving despite experiencing adversity, pressure, setbacks, or stress (Fourie and Potgieter, 2001; Clough et al., 2002; Galli and Vealey, 2008; Hosseini and Besharat, 2010). In fact, more recent resilience endeavors have outlined the core resilience protective factors among athletes, many of which are remarkably similar to the attributes of MT (e.g., confidence; Fletcher and Sarkar, 2012). This apparent resilience and MT overlap is further evidenced in the large amount of MT variability (i.e., 35\%) that was explained by the resilience subscales of perception of self, perception of future, social resources, and social competence.

The finding that resilience resources did not account for approximately $65 \%$ of the variability in MT may support the contention of resilience as a component of MT (Coulter et al., 2010; Sheard, 2013). That is, if resilience is a characteristic of MT, it may be one of several MT subcomponents (Gucciardi et al., 2008; Gucciardi and Gordon, 2009). On the other hand, a range of social, familial, community, and cultural resilience protective factors have also been identified in non-sport (e.g., Cowen et al., 1997; Honey et al., 2011) and in athletic populations (e.g., Sarkar and Fletcher, 2014). Although external protective resources may be related to MT (e.g., social resources), or, perhaps contribute to MT development (e.g., supportive social environment; Mahoney et al., 2014), the internal, individual, and personal nature of MT suggests that such facets of resilience are unlikely to comprise MT (Chang et al., 2012; Hardy et al., 2014). This may be supported by the present finding that both MT and resilience, collectively, significantly predicted stress. Therefore, both MT and resilience appear to contribute to the variability in stress levels beyond that of either construct alone, a reflection of the divergent components that comprise MT (i.e., internal) and resilience resources (i.e., internal and external).

There may also be theoretical and conceptual distinctions between MT and resilience. For instance, Sarkar and Fletcher (2014) discern adversity (i.e., an incident with negative connotations) from stressors (i.e., environmental demands), with adversity only considered to have occurred if post-stressor maladaptive behavior is representative of that which may be experienced by a typical member of the population. For athletes, who are exposed to many types of stressors that members of the normative population may not experience, perhaps resilience only applies when they experience stressors that may subsequently be considered adversity for an average member of the population (e.g., loss of a close family member).

Mental toughness, on the other hand, may apply more specifically to stressors and the resultant stress that athletes experience during sport training, competition, and postcompetition. Thus, although resilience may have a role in relation to overcoming stress, MT might be more important for negating or avoiding the detrimental effects of stress among athletes in sporting contexts, whereas resilience may be relevant primarily when experiencing more severe adversities that are likely to occur outside of sport participation.

\section{Mental Toughness and Stress}

The finding that MT is related to lower levels of stress corresponds with the assertion that MT is associated with positively adapting to stress (e.g., Jones et al., 2002; Gucciardi et al., 2009a). The results support prior research that has reported mentally tougher athletes experience lower levels of stress or self-perceived stressor severity (e.g., Middleton et al., 2004; Horsburgh et al., 2009; Kaiseler et al., 2009), though it extends the MT-stress relationship to a sport-specific context, competitive tennis. As Kaiseler et al. (2009) suggest, mentally tough athletes might appraise stressors as less intense, resulting in a more optimistic outlook and a lower stress response. It may also relate to their superior ability to control their thoughts and emotions (Golby and Sheard, 2004; Crust, 2009) that assists with the appraisal of stressors or their ability to employ more effective coping strategies (Nicholls et al., 2008; Crust and Keegan, 2010). Alternatively, mentally tough individuals may use a range of psychological strategies (e.g., relaxation techniques, self-talk, mental imagery) that assist them when they encounter stressors or experiences stress (Crust and Azadi, 2010; Mattie and MunroeChandler, 2012).

\section{Future Research Suggestions}

The findings in this study offer some key prospective directions for MT research. Specifically, a number of external resilience protective factors (e.g., social resources and social competence) were associated with greater MT, suggesting that a strong social support system, social interconnectedness, and interpersonal skills may be beneficial to MT. Similar types of external factors have been identified as important to the development of MT, including various interpersonal relationships (Bull et al., 2005; Connaughton et al., 2008, 2010; Gucciardi, 2011). Fostering an athlete's social skills, a network of meaningful others (e.g., coaching team, peers), and a socially supportive environment, both in and outside of sport, may have positive implications for MT (Crust and Clough, 2011). Therefore, future research could determine the extent to which interventions aimed at building athletes' social resources and interpersonal functioning, such as relationships with coaches and family, develop MT.

Based on the negative relationship between MT and stress found in this study, identifying sources of stress as well as an athlete's psychophysiological reactions to such may enable the alteration of debilitative perceptions and responses. Initial evidence suggests that mentally tough athletes' more opportunistic or facilitative appraisal of stressors assists them to experience lower stress responses (Kaiseler et al., 2009). Accordingly, investigating mentally tough athletes' cognitive framing of different stressors appears to be an important area to pursue, along with determining the potential to develop MT through challenging and altering athletes' dysfunctional appraisals of stressors (i.e., cognitive reframing; Crocker et al., 1988).

Another method through which negative stress responses may be avoided is through mentally tough athletes' apparent 
attentional control abilities (Gucciardi and Gordon, 2009). With the propensity to sustain concentration levels, remain focused, and avoid distractions, athletes high in MT may be less inclined to devote attention toward certain types of stressors (e.g., adverse weather conditions), and, resultantly, experience lower levels of stress. Prospective research could assess the propensity for mentally tough athletes to attend to certain stimuli and not others. Similarly, experimental designs examining the cognitive distractibility profiles of athletes high and low in MT are encouraged, particularly in relation to stressors that vary in severity.

Future research is also necessary to determine mentally tough outcomes or indicators (e.g., behaviors) as a function of sport type and situations that require MT in sport. Research differentiating MT and resilience is also warranted, including distinctions along the lines of the relevance, application, and outcomes associated with each construct in varied sport and non-sport contexts.

\section{Limitations}

There are selected limitations associated with the present study. Specifically, the cross-sectional design restricts conclusions of causality between the variables. Attempts to differentiate MT and resilience may require delineating the divergent circumstances in which the constructs may be relevant. Accompanying this is the necessity to generate consensus on the conceptualization of each construct as well as key definitions of the antecedents and consequences linked to both constructs (e.g., adversity, stressors, positive adaptation, outcomes). The sport specific focus of this study (i.e., tennis), as well as the inclusion of competitive tennis participants from South Africa, limits the ability to generalize the findings to other population groups. However, with sport-specific MT studies recommended (e.g., Crust, 2008) and indications of cross-cultural MT differences (e.g., Xinyi et al., 2004), this study

\section{REFERENCES}

Briggs, S., and Cheek, J. (1986). The role of factor analysis in the evaluation of personality scales. J. Pers. 54, 106-148. doi: 10.1111/j.1467-6494.1986.tb00391.x

Bull, S., Shambrook, C., James, W., and Brooks, J. (2005). Towards an understanding of mental toughness in elite English cricketers. J. Appl. Sport Psychol. 17, 209-227. doi: 10.1080/10413200591010085

Capanna, C., Stratta, P., Hjemdal, O., Collazzoni, A., and Rossi, A. (2015). The Italian validation study of the resilience scale for adults (RSA). Bollett. Psicol. Appl. 272, 16-24.

Chang, Y., Chi, L., and Huang, C. (2012). Mental toughness in sport: a review and prospect. Int. J. Sport Exerc. Psychol. 10, 79-92. doi: 10.1080/1612197X.2012.661202

Clough, P., Earle, K., Perry, J., and Crust, L. (2012). Comment on "Progressing measurement in mental toughness: a case example of the Mental Toughness Questionnaire 48" by Gucciardi. Hanton, and Mallett (2012). Sport Exerc. Perform. Psychol. 1, 283-287. doi: 10.1037/a0029771

Clough, P., Earle, K., and Sewell, D. (2002). "Mental toughness: the concept and its measurement," in Solutions in Sport Psychology, ed. I. Cockerill (London: Thomson Publisher), 32-45.

Cohen, J. (1992). A power primer. Psychol. Bull. 112, 155-159. doi: 10.1037/00332909.112.1.155

Connaughton, D., and Hanton, S. (2009). "Mental toughness in sport: conceptual and practical issues," in Advances in Applied Sport Psychology: A Review, eds S. Mellalieu and S. Hanton (London: Routledge), 317-346. afforded additional detail about the sport and culturally specific nature of MT.

In addition, although the RSA and SMTQ have been validated previously, the internal consistency of one subscale from each instrument was particularly low $(<0.60)$, which limited the application of these subscales in this study. With prior studies raising internal consistency concerns over selected SMTQ subscales (c.f. Crust and Swann, 2011) and recent SMTQ conceptual breadth criticisms (c.f. Gucciardi et al., 2011), it is suggested that further use of the SMTQ follows refinement of the instrument. Also, as resilience in sport applications advance, it may be necessary to develop, refine, and validate a measure of resilience for specific use among athletes.

\section{CONCLUSION}

The current study offers preliminary quantitative support for the interrelatedness between resilience and MT and extends the negative association between MT and stress to competitive tennis players, an athletic domain in which MT has been underexplored. The findings also offer initial evidence to suggest the distinct roles of resilience and MT in avoiding or alleviating stress, at least in competitive tennis. Additional research in this area is needed, especially along the lines of discerning MT from resilience and determining the contextual relevance of each construct in sport.

\section{AUTHOR CONTRIBUTIONS}

All authors listed, have made substantial, direct and intellectual contribution to the work, and approved it for publication.

Connaughton, D., Hanton, S., and Jones, G. (2010). The development and maintenance of mental toughness in the world's best performers. Sport Psychol. $24,168-193$.

Connaughton, D., Wadey, R., Hanton, S., and Jones, G. (2008). The development and maintenance of mental toughness: perceptions of elite performers. J. Sports Sci. 26, 83-95. doi: 10.1080/02640410701310958

Coulter, T., Mallett, C., and Gucciardi, D. (2010). Understanding mental toughness in Australian soccer: perceptions of players, parents, and coaches. J. Sports Sci. 28, 699-716. doi: 10.1080/02640411003734085

Cowden, R., Fuller, D., and Anshel, M. (2014). Psychological predictors of mental toughness in elite tennis: an exploratory study in learned resourcefulness and competitive trait anxiety. Percept. Mot. Skills 119, 661-678. doi: 10.2466/30.PMS.119c27z0

Cowen, E., Wyman, P., Work, W., Kim, J., Fagen, D., and Magnus, B. (1997). Follow-up study of young stress-affected and stress-resilient urban children. Dev. Psychopathol. 9, 565-577. doi: 10.1017/S0954579497001326

Crocker, P., Alderman, R., and Smith, F. (1988). Cognitive-affective stress management training with high performance youth volleyball players: effects on affect, cognition, and performance. J. Sport Exerc. Psychol. 10, 448-460.

Crocker, P., Tamminen, K., and Gaudreau, P. (2015). "Coping in sport," in Contemporary Advances in Sport Psychology: A Review, eds S. Mellalieu and S. Hanton (New York, NY: Routledge Publisher), 28-67.

Crust, L. (2008). A review and conceptual re-examination of mental toughness: implications for future researchers. Pers. Individ. Differ. 45, 576-583. doi: 10.1016/j.paid.2008.07.005 
Crust, L. (2009). The relationship between mental toughness and affect intensity. Pers. Individ. Differ. 47, 959-963. doi: 10.1016/j.paid.2009.07.023

Crust, L., and Azadi, K. (2010). Mental toughness and athletes' use of psychological strategies. Eur. J. Sport Sci. 10, 43-51. doi: 10.1080/17461390903049972

Crust, L., and Clough, P. (2011). Developing mental toughness: From research to practice. J. Sport Psychol. Action 2, 21-32. doi: 10.1080/21520704.2011.563436

Crust, L., and Keegan, R. (2010). Mental toughness and attitudes to risk-taking. Pers. Individ. Differ. 49, 164-168. doi: 10.1016/j.paid.2010.03.026

Crust, L., and Swann, C. (2011). Comparing two measures of mental toughness. Pers. Individ. Differ. 50, 217-221. doi: 10.1016/j.paid.2010.09.032

Fletcher, D., Hanton, S., and Mellalieu, S. (2006). "An organisational stress review: conceptual and theoretical issues in competitive sport," in Literature Reviews in Sport Psychology, eds S. Hanton and S. Mellalieu (Hauppauge, NY: Nova Science), 321-374.

Fletcher, D., and Sarkar, M. (2012). A grounded theory of psychological resilience in Olympic champions. Psychol. Sport Exerc. 13, 669-678. doi: 10.1016/j.psychsport.2012.04.007

Fourie, S., and Potgieter, J. (2001). The nature of mental toughness in sport. South Afr. J. Res. Sport Phys. Activity Recreat. 23, 63-72. doi: 10.1016/j.bjoms.2012.04.263

Friborg, O., Barlaug, D., Martinussen, M., Rosenvinge, J., and Hjemdal, O. (2005). Resilience in relation to personality and intelligence. Int. J. Methods Psychiatr. Res. 14, 29-42. doi: 10.1002/mpr.15

Friborg, O., Hjemdal, O., Rosenvinge, J., and Martinussen, M. (2003). A new rating scale for adult resilience: what are the central protective resources behind healthy adjustment? Int. J. Methods Psychiatr. Res. 12, 65-76. doi: $10.1002 / \mathrm{mpr} .143$

Galli, N., and Vealey, R. (2008). "Bouncing back" from adversity: athletes' experiences of resilience. Sport Psychol. 22, 316-335.

George, D., and Mallery, P. (2003). SPSS for Windows Step by Step: A Simple Guide and Reference. 11.0 Update, 4th Edn. Boston, MA: Allyn \& Bacon.

Gerber, M., Brand, S., Feldmeth, A., Lang, C., Elliot, C., Holsboer-Trachsler, E., et al. (2013a). Adolescents with high mental toughness adapt better to perceived stress: a longitudinal study with Swiss vocational students. Pers. Individ. Differ. 54, 808-814. doi: 10.1016/j.paid.2012.12.003

Gerber, M., Kalak, N., Lemola, S., Clough, P., Perry, J., Pühse, U., et al. (2013b). Are adolescents with high mental toughness levels more resilient against stress? Stress Health 29, 164-171. doi: 10.1002/smi.2447

Golby, J., and Sheard, M. (2004). Mental toughness and hardiness at different levels of rugby league. Pers. Individ. Differ. 37, 933-942. doi: 10.1016/j.paid.2003.10.015

Gonzalez-Boto, R., Salguero, A., Tuero, C., and Marquez, S. (2008). Spanish adaptation and analysis by structural equation modeling of an instrument for monitoring overtraining: the Recovery-Stress Questionnaire (RESTQ-Sport). Soc. Behav. Pers. 36, 635-650. doi: 10.2224/sbp.2008.36.5.635

Gucciardi, D. (2009). Do developmental differences in mental toughness exist between specialized and invested Australian footballers? Pers. Individ. Differ. 47, 985-989. doi: 10.1016/j.paid.2009.08.001

Gucciardi, D. (2011). The relationship between developmental experiences and mental toughness in adolescent cricketers. J. Sport Exerc. Psychol. 33, 370-393.

Gucciardi, D., and Gordon, S. (2009). Development and preliminary validation of the Cricket Mental Toughness Inventory (CMTI). J. Sports Sci. 27, 1293-1310. doi: 10.1080/02640410903242306

Gucciardi, D., Gordon, S., and Dimmock, J. (2008). Towards an understanding of mental toughness in Australian football. J. Appl. Sport Psychol. 20, 261-281. doi: $10.1080 / 10413200801998556$

Gucciardi, D., Gordon, S., and Dimmock, J. (2009a). Development and preliminary validation of a mental toughness inventory for Australian football. Psychol. Sport Exerc. 10, 201-209. doi: 10.1016/j.psychsport.2008.07.011

Gucciardi, D., Gordon, S., and Dimmock, J. (2009b). Advancing mental toughness research and theory using personal construct psychology. Int. Rev. Sport Exerc. Psychol. 2, 54-72. doi: 10.1080/17509840802705938

Gucciardi, D., Hanton, S., and Mallett, C. (2012). Progressing measurement in mental toughness: a case example of the Mental Toughness Questionnaire 48. Sport Exerc. Perform. Psychol. 1, 194-214. doi: 10.1037/a0027190

Gucciardi, D., Mallett, C., Hanrahan, S., and Gordon, S. (2011). "Measuring mental toughness in sport: current status and future directions," in Mental Toughness in Sport: Developments in Theory and Research, eds D. Gucciardi and S. Gordon (Abingdon: Routledge Publisher), 108-132.

Hardy, J., Imose, R., and Day, E. (2014). Relating trait and domain mental toughness to complex task learning. Pers. Individ. Differ. 68, 59-64. doi: 10.1016/j.paid.2014.04.011

Hardy, L., Bell, J., and Beattie, S. (2014). A neuropsychological model of mentally tough behavior. J. Pers. 82, 69-81. doi: 10.1111/jopy.12034

Herrman, H., Stewart, D., Diaz-Granados, N., Berger, E., Jackson, B., and Yuen, T. (2011). What is resilience? Can. J. Psychiatry 56, 258-265.

Hjemdal, O., Friborg, O., Braun, S., Kempenaers, C., Linkowski, P., and Fossion, P. (2011). The resilience scale for adults: construct validity and measurement in a belgian sample. Int. J. Test. 11, 53-70. doi: 10.1080/15305058.2010. 508570

Honey, K., Rees, P., and Griffey, S. (2011). Investigating self-perceptions and resilience in looked after children. Educ. Psychol. Pract. 27, 37-52. doi: $10.1080 / 02667363.2011 .549352$

Horsburgh, V., Schermer, J., Veselka, L., and Vernon, P. (2009). A behavioural genetic study of mental toughness and personality. Pers. Individ. Differ. 46, 100-105. doi: 10.1016/j.paid.2008.09.009

Hosseini, S., and Besharat, M. (2010). Relation of resilience with sport achievement and mental health in a sample of athletes. Proc. Soc. Behav. Sci. 5, 633-638. doi: 10.1016/j.sbspro.2010.07.156

Jones, G., Hanton, S., and Connaughton, D. (2002). What is this thing called mental toughness? An investigation of elite sport performers. J. Appl. Sport Psychol. 14, 205-218. doi: 10.1080/10413200290103509

Jones, G., Hanton, S., and Connaughton, D. (2007). A framework of mental toughness in the world's best performers. Sport Psychol. 21, 243-264.

Kaiseler, M., Polman, R., and Nicholls, A. (2009). Mental toughness, stress, stress appraisal, coping and coping effectiveness in sport. Pers. Individ. Differ. 47, 728-733. doi: 10.1016/j.paid.2009.06.012

Kellmann, M., and Kallus, K. (2001). Recovery-Stress Questionnaire for Athletes. User Manual. Champaign, IL: Human Kinetics.

Kobasa, S., Maddi, S., and Kahn, S. (1982). Hardiness and health: a prospective study. J. Pers. Soc. Psychol. 42, 168-177. doi: 10.1037/0022-3514.42.1.168

Kumpfer, K. (1999). "Factors and processes contributing to resilience: the resilience framework," in Resilience and Development: Positive Life Adaptations, eds M. Glantz and J. Johnson (New York, NY: Kluwer Academic), 179-223.

Loehr, J. (1986). Mental Toughness Training for Sports: Achieving Athletic Excellence. Lexington, MA: Stephen Greene.

Loehr, J. (1995). The New Mental Toughness Training for Sport. New York, NY: Penguin.

Luthar, S., and Cicchetti, D. (2000). The construct of resilience: implications for interventions and social policies. Dev. Psychopathol. 12, 857-885. doi: $10.1017 /$ S0954579400004156

Mahoney, J., Gucciardi, D., Mallett, C., and Ntoumanis, N. (2014). Adolescent performers' perspectives on mental toughness and its development: the utility of the bioecological model. Sport Psychol. 28, 233-244. doi: 10.1123/tsp.2013-0050

Mancini, A., and Bonanno, G. (2009). Predictors and parameters of resilience to loss: toward an individual differences model. J. Pers. 77, 1805-1832. doi: 10.1111/j.1467-6494.2009.00601.x

Mattie, P., and Munroe-Chandler, K. (2012). Examining the relationship between mental toughness and imagery use. J. Appl. Sport Psychol. 24, 144-156. doi: $10.1080 / 10413200.2011 .605422$

McGrath, J. (1970). "A conceptual formulation for research on stress," in Social and Psychological Factors in Stress, ed. J. McGrath (New York, NY: Holt, Rinehart \& Winston), 1-13.

Middleton, S., Marsh, H., Martin, A., Richards, G., and Perry, C. (2004). "Discovering mental toughness: A qualitative study of mental toughness in elite athletes," in Proceeding of the Self Research Centre Biannual Conference, Berlin. Available at: http://www. sectiononewrestling.com/discovering_mental_toughness.pdf

Nederhof, E., Brink, M., and Lemmink, K. (2008). Reliability and validity of the Dutch Recovery Stress Questionnaire for Athletes. Int. J. Sport Psychol. 39, 301-311.

Nicholls, A., Polman, R., Levy, A., and Backhouse, S. (2008). Mental toughness, optimism, pessimism, and coping among athletes. Pers. Individ. Differ. 44, 1182-1192. doi: 10.1016/j.paid.2007.11.011 
Nunnally, J., and Bernstein, I. (1994). Psychometric Theory, 3rd Edn. New York, NY: McGraw-Hill.

Parkes, J., and Mallett, C. (2011). Developing mental toughness: attributional style retraining in rugby. Sport Psychol. 25, 269-287.

Perry, J., Clough, P., Crust, L., Earle, K., and Nicholls, A. (2013). Factorial validity of the Mental Toughness Questionnaire-48. Pers. Individ. Differ. 54, 587-592. doi: 10.1016/j.paid.2012.11.020

Punamaki, R., Qouta, S., Montgomery, E., and El Sarraj, E. (2006). Psychological distress and resources among siblings and parents exposed to traumatic events. Int. J. Dev. Behav. 30, 1-13.

Rosenbaum, M. (1990). "The role of learned resourcefulness in the self-control of health behavior," in Learned Resourcefulness: On Coping Skills, Self-Control and Adaptive Behavior, ed. M. Rosenbaum (New York, NY: Springer), 3-30.

Sarkar, M., and Fletcher, D. (2014). Psychological resilience in sport performers: a review of stressors and protective factors. J. Sports Sci. 32, 1419-1434. doi: $10.1080 / 02640414.2014 .901551$

Sheard, M. (2013). Mental Toughness: The Mindset Behind Sporting Achievement, 2nd Edn. New York, NY: Routledge Publisher.

Sheard, M., Golby, J., and van Wersch, A. (2009). Progress toward construct validation of the Sports Mental Toughness Questionnaire. Eur. J. Psychol. Assess. 25, 186-193. doi: 10.1027/1015-5759.25.3.186
Tibbert, S., Andersen, M., and Morris, T. (2015). What a difference a "Mentally Toughening" year makes: the acculturation of a rookie. Psychol. Sport Exerc. 17, 68-78. doi: 10.1016/j.psychsport.2014. 10.007

Windle, G. (2011). What is resilience? A review and concept analysis. Rev. Clin. Gerontol. 21, 152-169. doi: 10.1017/S0959259810000420

Xinyi, Z., Smith, D., and Adegbola, O. (2004). A cross-cultural comparison of six mental qualities among Singaporean, North American, Chinese, and Nigerian professional athletes. Int. J. Sport Exerc. Psychol. 2, 103-118. doi: 10.1080/1612197X.2004.96717

Conflict of Interest Statement: The authors declare that the research was conducted in the absence of any commercial or financial relationships that could be construed as a potential conflict of interest.

Copyright $\odot 2016$ Cowden, Meyer-Weitz and Oppong Asante. This is an open-access article distributed under the terms of the Creative Commons Attribution License (CC BY). The use, distribution or reproduction in other forums is permitted, provided the original author(s) or licensor are credited and that the original publication in this journal is cited, in accordance with accepted academic practice. No use, distribution or reproduction is permitted which does not comply with these terms. 